\title{
Cyanoacrylate Vein Glue and Allergy - A Real Problem ?
}

\author{
Dr. Ulf Th. Zierau Saphenion \\ Venenzentren Berlin / Rostock \\ *Corresponding Author - Dr. Ulf Th. Zierau Saphenion
}

Received 16 February 2019;

Accepted 02 March 2019;

Published 11 March 2019

\begin{abstract}
Vein Glue and allergy - is there a significant risk?

In a few specialist comments and articles by phlebologically active colleagues is repeatedly warned against the emergence of an allergy to the cyanoacrylate used in the vein glue. Reason enough for us to compare our own experience with the use of the vein adhesive with the worldwide specialist literature.
\end{abstract}

Keywords: sealing varicose veins, cyanoacrylate vein glue.

\section{Introduction}

In the base, all varicose veins should be treated actively. This we can find in nearly all guidelines worldwide.

Since 20 years by now, varicosis has been increasingly treated endovenously. Before this, the varicose veins were treated radically with the "stripping" - method, a 112 years old radical surgery method.

At the start, the VNUS® Closure Plus procedure and linear laser procedure were used, and these were followed in 2006/2007 by the bipolar RFITT ${ }^{\circledR}$ catheter, the VNUS ${ }^{\circledR}$ ClosureFast system and the radial laser. Thus, in the course of the last few years, plenty of experience has been gathered with endoluminal therapy, quality criteria have been defined and standards for the different techniques have been developed ${ }^{[1-8]}$.

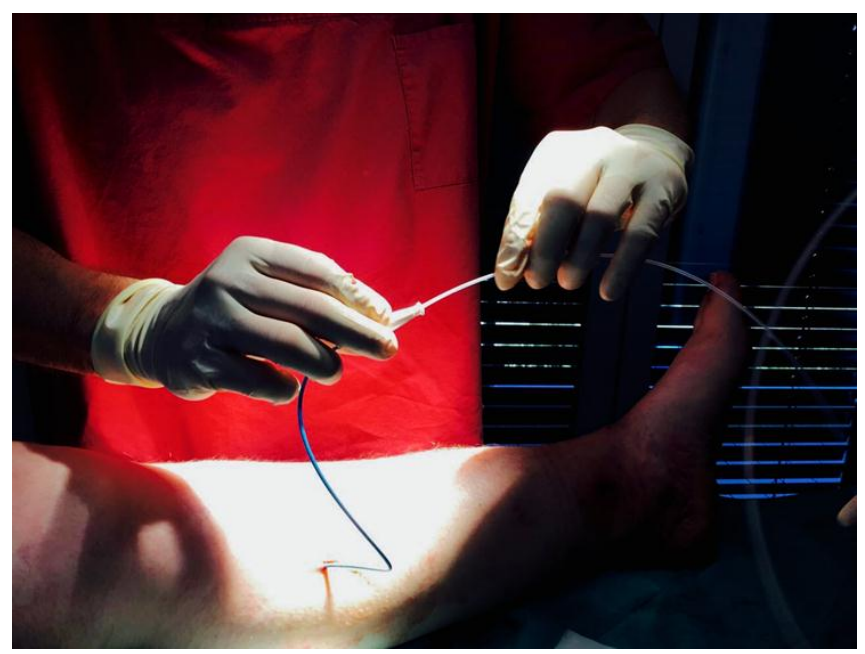

Fig.1: VenaSeal Closure System
Nearly 17 years ago the development of a fascinatingly simple, yet nevertheless highly effective method of sealing veins - the VenaSeal ${ }^{\circledR}$ closure technique - was initiated. After CE - approval had been granted in the autumn of 2011, a number of vein centers in Germany and Europe started using the VenaSeal ${ }^{\circledR}$ system $^{[1,2,3,9,10]}$

In this relation very interesting - sealing veins is not a new method one - also since the middle of twenties we find sealing techniques.

Today there is an approval in all countries, also in USA since $2 /$ 2015.

The author has applied Venaseal for the first time in a great saphenous vein on 1st. August 2012.

\section{Material and method}

Based on the manufacturer's application instructions, sealing with the VenaSeal - system was started $1-3 \mathrm{~cm}$ from the saphenofemoral junction, and a spot of glue was applied at intervals of $2-3 \mathrm{~cm}$, depending on the diameter and the flow / pressure of the vein. Thick branch - offs of auxiliary side branches were additionally treated with single - shot glue. The maximal diameter of treated truncal veins was $2,3 \mathrm{~cm}$, also venous aneurysmas, ectatic veins and perforators were treatet. In the middle we need 1,6 - 1,8 $\mathrm{ml}$ of glue for every truncal vein.

The follow - up observation period in our study was up to 78 months.

The great saphenous vein was treated in 1503 cases, in 563 cases the small saphenous vein was treated and in 103 cases the trunc of an inguinal accessoric vein was sealed. Two Giacomini`s veins and 
5 femoropopliteal veins also were treated. In summary we treated 2176 truncal veins in 1170 cases.

In 13 cases we treated truncal veins with ulcers cures, we also treated patients with HIV, hepatitis, Parkinson and multi allergy patients.

VenaSeal ${ }^{\circledR}$ interventions were performed under light sedation with Dormicum or local anesthesia for venous access accompanied by music therapy, 121 patients $(10,4 \%)$ did nt got any anaesthesia or sedation. One patient performed pain acupuncture on herself.

All patients are given a follow - up examination by clinical symptoms and by duplex sonography in the scope of a prospective study (our own quality management) on the 1st / 14 - 30th. / 70 90th. day as well as after 6 and 12 months. After this we controlled every following year.

\section{Results}

During the time period from 1st. August 2012 to 15 st. February 2019 (78 month), Venaseal ${ }^{\circledR}$ was applied to achieve closure of the vein in 2176 truncal varicose veins.

Grade 2 - 3 saphenous varicosis of the GSV according to Hach, and in the case of the SSV and acc. saphenous varicose veins grade 2 to Hach, was the inclusion criterium. In accessoric veins we treatet the inguinal trunc in length between $15-30 \mathrm{~cm}$.

In 1408 saphenous veins $(65,1 \%)$ were followed up over a 6 - 8 month time period, and 50 partial and 29 complete recanalizations were found, resulting in an effectiveness of $96,35 \%$. No further recanalizations were found after 78 month.

No allergy in 78 month using vein glue!

Our 78 month experience in using varicose vein glue did not show any allergies in all 2176 treated truncal veins. By default, we perform regular clinical and ultrasound follow - ups of treated veins. So far we have not been reported allergic, nor have we found any clinical signs of allergies or allergic symptoms. This affected all treated patients, including those who reported in the preoperative preparation and the discussions about allergies or as a multi - allergy sufferer had a corresponding allergy pass.

As previously stated, all our self - payer patients receive a warranty card on the effectiveness of the adhesive procedure. This is a 3 year warranty on the therapeutic effect and possibly free repetition of the glue associated. In this context of warranty, we have treated a second intervention with sealing glue in 19 patients - this also includes my own mother.

In no case did any kind of intolerance or allergy appear after the repeated second therapy.

This fact speaks against the conjecture of colleague Dr. Joachim Thun, that allergies may occur during recurrent interventions. In the same sheet reported Dr. Neff of 56 glue - treated truncal varicose veins, also all without an allergy $(12,21)$

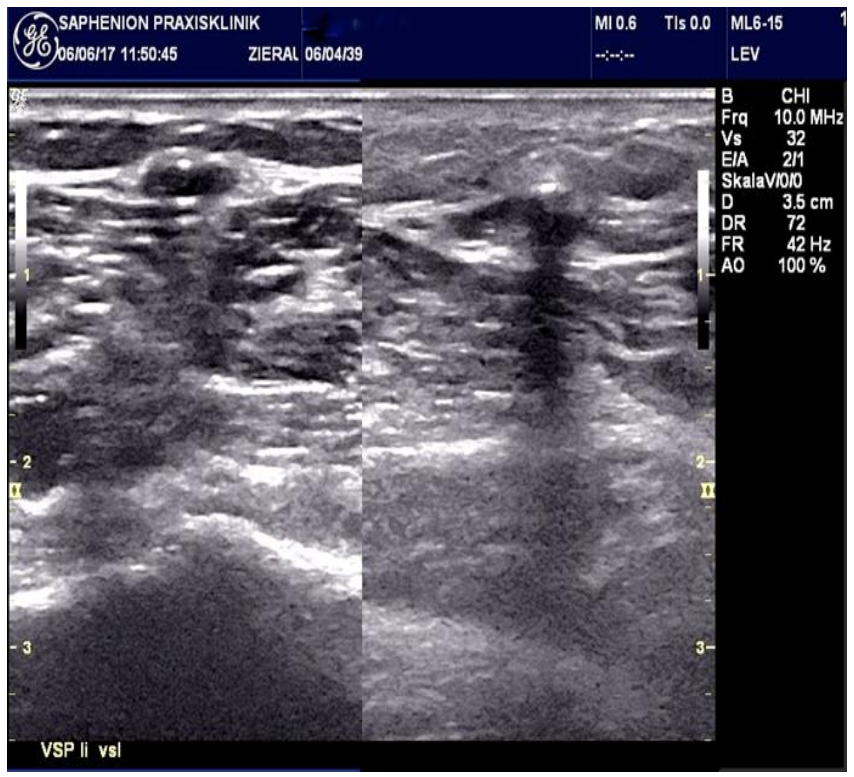

Fig.2: GSV after sealing with cyanoacrylate glue

\section{Discussion}

In the last 20 years, the necessary quality criterias for endovascular interventions on veins with varicose changes were largely laid down, and several comparative studies on functional efficiency of radical stripping surgery on the one hand and endovenous treatments on the other hand were furthermore conducted. By now, it has emerged as an undeniable fact that endovenous interventions do not only exhibit a merely cosmetic advantage as was hitherto assumed. They also have clinical advantages and quite significantly reduce side effects and complications such as still occur regularly today as in the past in connection with the conventional surgical technique.

Thus, the colleagues who work with endovenous procedures meanwhile have reliable criteria for a high - quality therapy ${ }^{[1-7][13-}$ 25]

The VenaSeal - closure procedure is the newest technical development in the series of endovenous therapeutic procedures. Although it is a catheter - based procedure in terms of the basic principle of the therapeutic approach, it differs fundamentally with regard to the closure technique. While the glue likewise gives rise to a certain temperature (approx. $45-50^{\circ} \mathrm{C}$ ), the procedure is not a thermal one. Side effects as those known to occur in connection with laser and radio wave therapy ultimately play no significant role here. The necessary reliable closure is achieved by means of non tumescent non thermal cyanoacrylate superglue, the basic chemical formula of which has been known since several decades, and which is being used in nearly all kinds of operative medicine.

By the way - the sealing therapy is not a new idea - also in the Golden Twenties german surgeons and phlebologists have sealed truncal varicose veins with glucose solution. Also the world known surgeon Ferdinand Sauerbruch was a friend of sealing, Since 1928 / 1929 all patients in Sauerbruch`s hospital Charitè Berlin, treated by truncal varicose veins, were sealed ${ }^{[26]}$.

\section{Facts from scientific literature}

We found in retrospective last 35 years only 23 (!) papers on the subject of cyanoacrylate allergy ${ }^{[27-41]}$. Not all articles describe allergic reactions. The majority of the articles were published by dermatologists and aesthetics. All publications are case 
descriptions. Compared to the number of patients using cyanoacrylate glue, these numbers are negligible.

Essentially it is about the suspicion of allergic skin reactions / inflammation / foreign body - reactions in the closure of surgical wounds of skin medicine (tumors, fat tumors etc). However, the described cases are - in relation to the number of treated patients purely case - by - case descriptions.

Other reports come from the field of aesthetics. For example, contact allergies have been described in the bonding of artificial fingernails and eyebrows. In some cases, allergic rhinitis and asthma attacks have been described. The latter were mainly noticed by the inhalation of adhesive vapors and skin contact.

Even when working with cyanoacrylate adhesives in model making, it has come in one case described an asthma attack.

In the final analysis, the new sealing procedure has to meet solely the hard criterion of efficacy, namely the permanence of an effective vein closure. And as far as this aspect is concerned, both the first results of the eSCOPE study ${ }^{[14]}$ and the results of single center studies, and also currently of the VeClose study ${ }^{[7,11]}$ are very good. The closure rate is similarly high as that achieved with radio waves, namely between $93-100 \%$ when all results are summarized.

Thus, the Sealing - procedure appears to be on the same level with, or even superior to the high - frequency radio wave system $^{[13,15,16,24]}$. In the time periods between 12 and 36 months covered by follow - up examinations up to now, both procedures have proven quite clearly superior $(99,6 \%)^{[16,25]}$ to laser therapy in terms of effectiveness.

No one of the published papers present an allergic reaction.

\section{Allergy potential of the vein glue overestimated}

We believe that statements about the allergenic risk of vein glue are sometimes overstated. On the one hand, only very small amounts of the adhesive - approx. $1.2-1.8 \mathrm{ml}$ per trunk vein - are introduced into the vein via catheter. On the other hand, there are only very few individual case descriptions for the general topic "cyanoacrylate glue and allergy".

Of course, as with any drug, an explanation of the problem of a possible allergy must be made. However, the risk of actually developing allergic reactions is negligible in sealing veins. This must be communicated in any case. A blanket suspicion of allergic side effects is completely out of place.

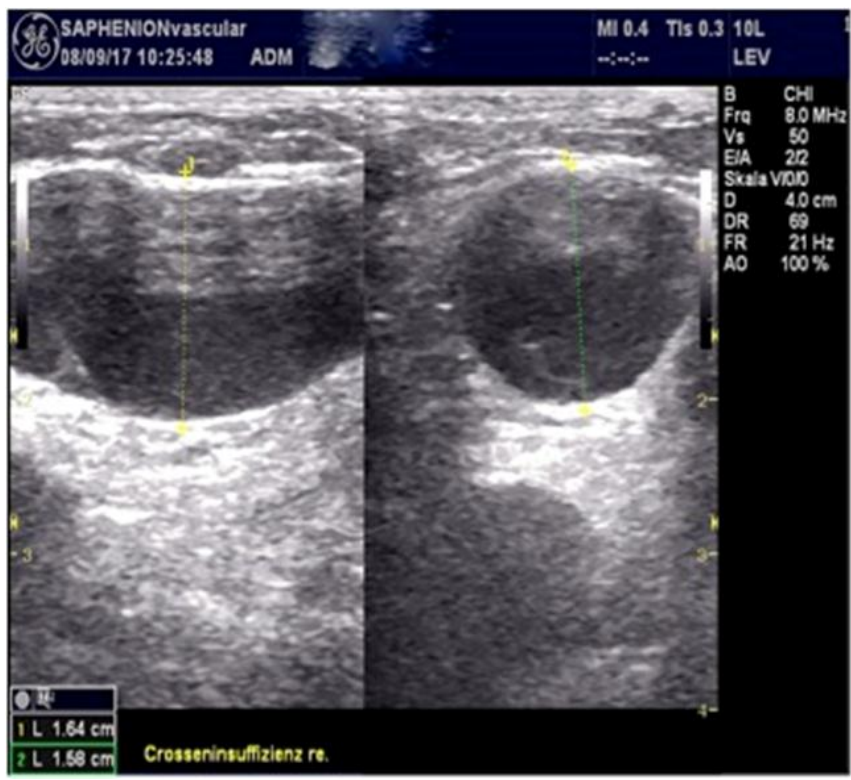

Fig.3: Sealing ectatic and aneurysmatic parts of truncal veins is also possible with a little bit more of glue - also these cases didn't show any allergic reactions.

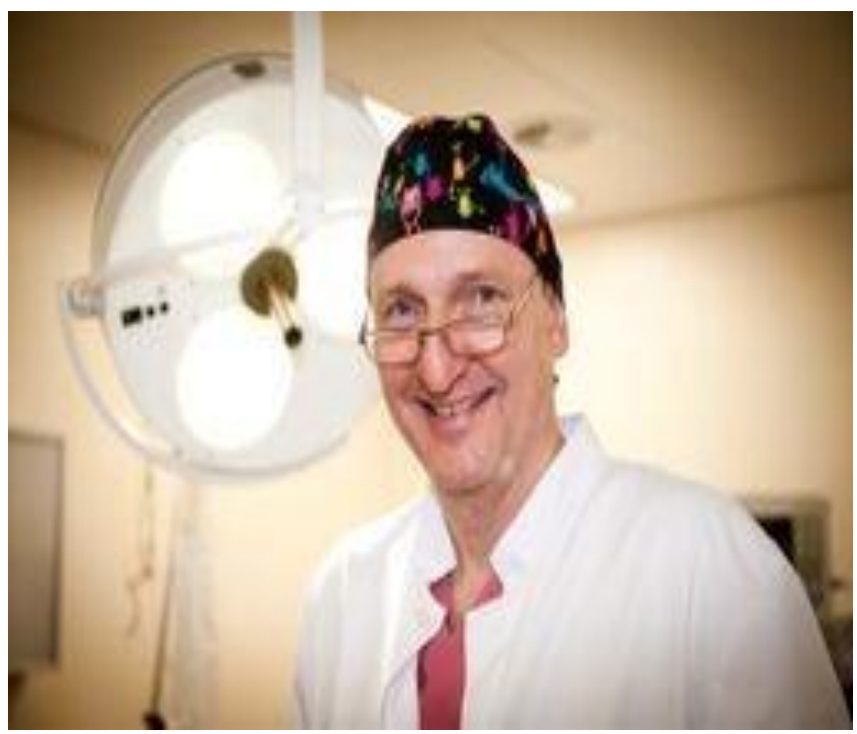

Fig.4: Dr. Ulf Th.Zierau

\section{Our Statement}

By now, VenaSeal ${ }^{\circledR}$ has undeniably become at SAPHENION the therapy of first choice for the treatment of the truncal varicose veins. In the light of the 18 years of experience we have gathered by now, we recommend that every vein center that applies endovenous treatment should have at least 2 alternative treatment procedures at its disposal.

Independently of this and including all experiences with modifications of the sealing technique we at SAPHENION® meanwhile regard the non tumescent, non thermal Sealing Therapy as treatment of first choice in the range of catheter - supported therapeutic procedures in truncal varicose veins GSV, SSV or VSAA.

We believe that statements about the allergenic risk of vein glue are sometimes overstated. And we are convinced, that we can treat all truncal varicose veins in one session, we can treat dilated veins and venous aneurysms with a little bit more of glue without any risk of allergy. 
But: It's very important to inject the glue only exactly inside the vessel, injection in tissue or in wounds can cause an allergic reaction.

\section{Conflict of interests:}

There are no conflicts of interest; the present research paper was not sponsored.

\section{Bibliography / Links:}

[1] Almeida JI, Min RJ, Raabe R, McLean DJ, Madsen M.: Cyanoacrylate adhesive for the closure of truncal veins: 60-day swine model results. Vasc Endovasc Surg 2011; 45: 631-635

[2] Almeida JI, Mackay EG, Bautista C, Proebstle T.: Cyanoacrylate glue great saphenous vein ablation: preliminary 180 - day follow up of a first - in - man feasibility study of a no-compression - no - local anaesthesia technique. J.Vasc Surg 2012; 55:297.

[3] Almeida, JI, Julian J. Javier, Ed Mackay, Claudia Bautista, Thomas M. Proebstle: One - Year follow up of first human use of cyanoacrylate adhesive for treatment of saphenous vein incompetence: epub 20. dec. 2012.

[4] Creton D, Rea B, Pittaluga P, Chastanet S, Allaert FA. Evaluation of the pain in varicose vein surgery under tumescent local anaesthesia using sodium bicarbonate as excipient without any intravenous sedation. Phlebology 2011. (Epub ahead of print 21 November 2012)

[5] Elias S, Raines JK. Mechanochemical tumescentless endovenous ablation: final results of the initial clinical trial. Phlebology.

[6] Huisman LC, Bruins RMG, van den Berg M, Hissink RJ. Endovenous laser ablation of the small saphenous vein: prospective analysis of 150 patients, a cohort study. Eur J Vasc Endovasc Surg 2009; 38:199-202.

[7] Gibson et al:: Twenty-four month results from a randomized trial of cyanoacrylate closure versus radiofrequency ablation for the treatment of incompetent great saphenous veins. J Vasc Surg Venous Lymphat Disord. 2018 Sep; 6(5):606-613.

[8] Keel D, Goldman MP. Tumescent anaesthesia in ambulatory phlebectomy: addition of epinephrine. Dermatol Surg 1999; 25:371-2.

[9] Lawson J, S Gauw, C van Vlijmen, P Pronk, M Gaastra, M Mooij, C Wittens: Sapheon: the solution? Phlebology 2013;0:1-8

[10] Min RJ, Almeida JI, McLean DJ, Madsen M, Raabe R.: Novel vein closure procedere using a proprietary cyanoacrylate adhesive: 30-day swine model results. Phlebology 2012; epub jan. 2012

[11] Morrison, Nick and Kathleen Gibson: Veclose Study: Preliminary Month 1 Data; 2nd Annual Cyanoacrylate Embolization Symposium Mainz, Jan. 18, 2014.

[12] Neff, P.: Erfahrungen mit viskösem Cyanoacrylat in der Niederlassung - Patientenauswahl und Ergebnisse; vasomed 1, 2019; $31-33$.

[13] Proebstle TM, Vago B, Alm J, Göckeritz O, Lebard C, Pichot $\mathrm{O}$. Treatment of the incompetent great saphenous vein by endovenous radiofrequency powered segmental thermal ablation: first clinical experience. J Vasc Surg 2008; 47:151-6.
[14] Proebstle TM, Alm J, Rasmussen L, Dimitri S, Lawson JA, Whiteley M, Franklin IJ , Davies AH The European Multicenter Study On Cyanoacrylate Embolization Of Refluxing Great Saphenous Veins Without Tumescent Anaesthesia And Without Compression Therapy. eScope - study Abstract presented to the American Venous Forum Annual Meeting 2013, Phoenix ( AZ) USA

[15] 15. Proebstle TM, Alm J, Rasmussen L, Dimitri S, Whiteley M, Franklin IJ, Davies AH Cyanoacrylate Adhesive For Treatment of Great Saphenous Vein Incompetence without Tumescent Anesthesia and without Compression Therapy Abstract presented to the American College of Phlebology Annual Meeting 2012 Hollywood, Florida.

[16] Rasmussen LH, Bjoern L, Lawaetz M, Lawaetz B, Blemings A, Eklof B.: Randomised clinical trial comparing endovenous laser ablation with stripping of the great Saphenous vein: clinical outcome and recurrence after 2years. Eur J Vasc Endovasc Surg 2010;39:630 - 35

[17] Razek AA, Fouda NS, Elmetwaley N, Elbogdady E. Sonography of the knee joint. J Ultrasound 2009;12:5360.

[18] Rosen RJ, Contractor S: The use of cyanoacrylate adhesives in the management of congenital vascular malformations. Sem Interv Radiol 2004; 21:59-66

[19] Shadid N, Ceulen R, Nelemans P, et al. Randomized clinical trial of ultrasound-guided foam sclerotherapy versus surgery for the incompetent great saphenous vein. Br J Surg 2012;99:1062 - 70

[20] Shepherd AC, Gohel MS, Lim CS, Hamish M, Davies $\mathrm{AH}$. The treatment of varicose veins: an investigation of patient preferences and expectations. Phlebology 2010; 25:54-65.

[21] Thum J: Single Center Erfahrungen aus 234 Stammvenenbehandlungen mit viskösem n - Butyl - 2 Cyanoacrylat- Verwendbarkeit, Akzeptanz, Ergebnisse; vasomed 1, 2019; $28-31$

[22] Watts TJ et al.: Allergic contact dermatitis caused by VenaSeal tissue adhesive; Contact Dermatitis. 2018, Dec.24

[23] Zierau UTh: VenaSeal® - Therapie bei SAPHENION 18 Monats - Ergebnisse an 379 Stammvenen; Vortrag auf dem 2. Symposium zur VenaSeal ${ }^{\circledR}$ - Closure-Therapie, Mainz 18.01.2014

[24] Zierau UTh.: Venenverklebung versus Radiofrequenztherapie bei Varicosis - Verlaufsstudie über 36 Monate mit 1139 Behandlungen. vasomed 28 (2016) 212 - 216.

[25] Zierau UTh.: http://www.saphenion.de/news/konsensus1-neef-endovenoese-krampfadertherapie/

[26] Zierau UTh and Lahl W: The Fate of "Saphena" - Views into the Past; Journal of Vascular and Endovascular Therapy; 2018; Vol.3 No.4: 23

\section{Weblinks:}

[27] https://www.ncbi.nlm.nih.gov/pubmed/11350310

[28] https://www.ncbi.nlm.nih.gov/pubmed/29240057

[29] https://www.ncbi.nlm.nih.gov/pubmed/29164689

[30] https://www.ncbi.nlm.nih.gov/pubmed/28971138

[31] https://www.ncbi.nlm.nih.gov/pubmed/28893128

[32] https://www.ncbi.nlm.nih.gov/pubmed/26229511

[33] https://www.ncbi.nlm.nih.gov/pubmed/24125099

[34] https://www.ncbi.nlm.nih.gov/pubmed/23553564 
[35] https://www.ncbi.nlm.nih.gov/pubmed/23039005

[36] https://www.ncbi.nlm.nih.gov/pubmed/7774187

[37] https://www.ncbi.nlm.nih.gov/pubmed/7941055

[38] https://www.ncbi.nlm.nih.gov/pubmed/3661662

[39] https://www.ncbi.nlm.nih.gov/pubmed/3885815

[40] https://www.ncbi.nlm.nih.gov/pubmed/30582174

[41] http://www.saphenion.de/news/venenkleber/

[42] http://www.saphenion.de/news/special-case-sealingveins-with-hiv-der-besondere-fall-venenkleben-bei-hiv/

\section{Address of the author}

\section{Dr. U. Th. Zierau}

SAPHENION vascular Berlin.Rostock

Friedrichstraße 95, 10117 Berlin; berlin@saphenion.de

Steuerbordstraße 9, 18147 Rostock, rostock@saphenion.de www.saphenion.de 